\title{
The Investigation of Jordanian Education Ministry Employees' Attitude toward the Using of Cloud ERP
}

\author{
Hassan Alhanatleh, Murat Akkaya \\ Department of Management Information Systems, Girne American University, Kyrenia, Cyprus \\ Email: hassan_hanatleh@yahoo.com, muratakkaya@gau.edu.tr
}

How to cite this paper: Alhanatleh, $\mathrm{H}$. and Akkaya, M. (2016) The Investigation of Jordanian Education Ministry Employees' Attitude toward the Using of Cloud ERP. Int. J. Communications, Network and System Sciences, 9, 440-450.

http://dx.doi.org/10.4236/ijcns.2016.911036

Received: May 3, 2016

Accepted: November 8, 2016

Published: November 11, 2016

Copyright $\odot 2016$ by authors and Scientific Research Publishing Inc. This work is licensed under the Creative Commons Attribution International License (CC BY 4.0).

http://creativecommons.org/licenses/by/4.0/

\begin{abstract}
ERP systems have become an optimal solution for companies to perform their works with maximum advantages of Enterprise Resources Planning (ERP). Moreover, even though the cloud computing has many obstacles which need to be solved, but the enterprises always embrace the cloud. Many enterprises tend to adopt the cloud computing paradigm in order to get its leverage in successful and benefits. With the development of cloud computing technology, there is a growing orientation to move the ERP from inside boundaries of organizations into the cloud computing technologies. In addition, there were many studies that covered the cloud ERP without concentrating on acceptance the end user for this technology. Thus, this study comes to increase the understanding the attitude of the end user for cloud ERP technology. The main aim of this study is to investigate the employees' attitude towards use of cloud ERP. The conceptual research framework of cloud ERP is prepared based on the technology acceptance model (TAM). The employees of Queen Rania Center (QRC) in Jordanian Education Ministry used the cloud ERP system which implemented according to this study. The questionnaires are distributed online to the sample. The results indicate that the QRC employees enjoyed using the cloud ERP system.
\end{abstract}

\section{Keywords}

Enterprise Resources Planning (ERP), Cloud Computing, Cloud ERP, Jordanian Education Ministry, TAM, Perceived Usefulness, Ease of Use, Employee Attitude, Queen Rania Center (QRC)

\section{Introduction}

The main aim of Management Information Systems is to present the information which 
is sent from different levels of the organizations to managers. After that, the information is introduced to managers in order to be used in different areas in the organizations such as improving performance, decision making, planning, and increasing revenue [1]. Thus, the MIS supports the operational, tactical and strategic level for organizations by streaming the information through these levels.

Recently, cloud computing has played an essential role in the ICT area. In the next years, cloud computing will be considered as a successful system in many domains such as IT. According to [2], the importance of cloud computing refers to its advantages and benefits. Cloud providers present three types of services Infrastructure as a Service (IaaS), Platform as a Service (PaaS) and Software as a Service (SaaS). Moreover, SaaS service lists many issues which support business model in order to boost the system performance and decrease the drawbacks of traditional ERP. Secondly, the costs and hardware will be reduced. Finally, the cloud services can be improved through a private cloud, community cloud, public cloud or hybrid cloud. Therefore, the combination between ERP and cloud computing could help the organizations to improve their performance in order to increase revenue and take a high position in the competitive market. Furthermore, there are many advantages of cloud ERP available, for example it doesn't require the deployment of heavy expenditures while possible with less staff to operate, reducing service costs and easy to expand while provide mobility [3].

According to [4], it is found that there was a significant influence of using EduWave system in QRC from students and teachers' perspective while the role of the trust process in the EduWave system was not upheld. Thus, the EduWave system constrains on the duties which are related with educational domain and school information and others. However, the EduWave does not highlight on the some duties that are important to perform this work.

QRC is a part from education ministry in Jordan. The mission of QRC is to be a major provider to support learning and e-learning, including all the necessary resources for both students and teachers, schools and the community. The main aim of QRC is to present the information technology services through QRC system such as E-learning, perform some tedious procedures which are related with employees, and contain all information which are engaged with schools (building, teachers and students). Thus, the QRC system is considered as the first step to integrate all entities in ministry of education. The system serves around 80,000 teachers, 1.5 million students and the employees who are separated across the education directorates in different geographical area in Jordan.

\section{Research Framework}

According to [5], the Technology Acceptance Model (TAM) considers as the most important model in the researches which are decided in the information systems to find out the susceptibility of end users to use and accept of information systems and information technology. In addition, TAM has two determinants which are perceived ease of use and perceived usefulness.

According to [6], perceived usefulness was explained as "the degree to which a per- 
son believes that using a particular system would enhance his or her job performance".

Moreover, based on [6], perceived ease-of-use was demonstrated as "the degree to which a person believes that using a particular system would be free from effort". Consequently, both of determinants can investigate the weather success of information systems.

Consequently, in order to investigate the effects of the external factors on attitudes towards the use of cloud ERP. TAM is utilized (Figure 1), this refers to TAM ability to measure end users' acceptance of information technology.

Figure 1 shows the research framework of study. The relationship between independent variables and the attitude towards the cloud ERP system is presented in the below Figure 1. Here, two independent variables are shown which are technology factors and employee factors.

The technology factors depend on the information quality, system quality and service quality. Depending of [7], the first and third hypotheses are formulated. Moreover, the second and fourth hypotheses are adapted according to [7].

First hypothesis: Technology factors have a significant influences associated with a perceived usefulness towards cloud ERP.

Second hypothesis: Employee factors have a significant influences associated with a perceived usefulness towards cloud ERP.

Third hypothesis: Technology factors have significant influence associated with a perceived ease of use towards cloud ERP.

Fourth hypothesis: Employee factors have significant influence associated with a perceived ease of use towards cloud ERP.

The fifth and sixth hypotheses are adapted according to [6], where the perceived usefulness and perceived ease of use discovered that there was a positive effect on users' attitude towards the acceptance of new technology.

Fifth hypothesis: Perceived usefulness has significant influence associated with attitudes towards the use of cloud ERP.

Sixth hypothesis: Perceived ease of use has significant influence associated with attitudes towards the use of cloud ERP.

\section{Research Methodology}

This section is to deal with study data analysis. Thus, the used methodology will define the analysis type that will be used for gathered data. According to [8], the gather data

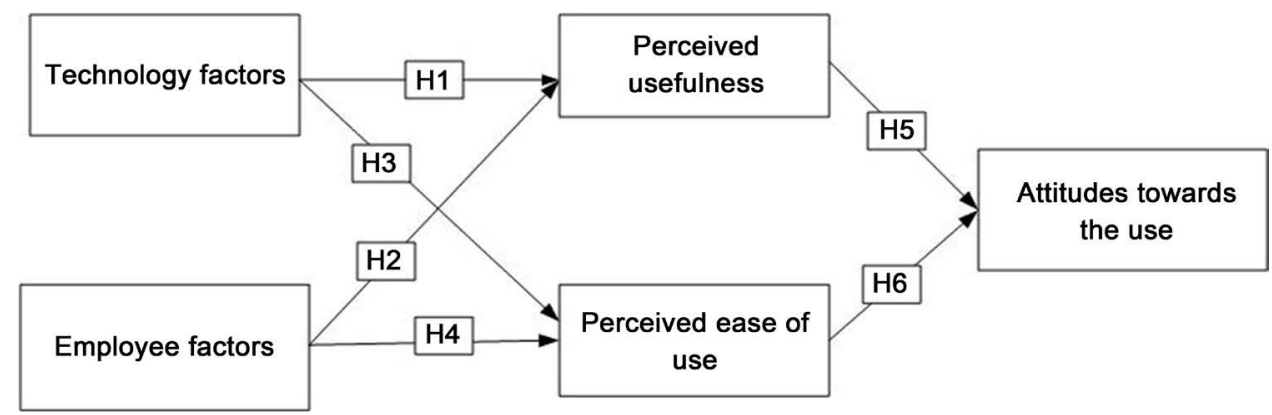

Figure 1. Research framework. 
which comes from spreading the designed survey on the selected sample is analyzed by quantitative analysis. In addition, in order to test hypothesis, SPSS software is used.

\subsection{Sampling}

The final version of study questionnaire is spread to the sample from the target population who are the QRC employees at Jordanian Education Ministry. The participants of sample are 206.

Gmail is used to prepare the online questionnaire in order to keep effortless, cost and time. Moreover, the online questionnaire has a password to confirm that the questionnaire is secured for the sample members only. Consequently, the employees who are chosen to complete the questionnaire filling come from three levels of Jordanian Education Ministry Management (operational, tactical and strategic). The members are distributed in different geographical area in Jordanian Hashemite Kingdom. The random technique was used to determine the size of the sample which consisted of 206 employees.

\subsection{Instrument}

Technology factors and employees' factors indicate as independent variables while perceived usefulness towards cloud ERP, perceived ease of use towards cloud ERP and attitudes towards use of cloud ERP indicate as dependent variables. Depending of these variables, the questionnaire was prepared to measure the perception on the attitude towards the use of cloud ERP environment. According to [6], the dependent variables are adapted while the independent variables are adapted according to [7]. In this study, the five-point Likert scale are used, where the ranking of this scale from "Strongly disagree" to "Strongly agree".

\subsection{Data Analysis}

\subsubsection{Sample Characteristics}

Table 1 lists the distribution of the study sample according to demographic variables. Consequently, the table demonstrates that the study sample consists more males than females. The number of males are (135) with (65.5\%), whereas the number of females are (71) with (34.5) from three level of management (Strategic, Tactical, operational) in Jordanian Education Ministry.

Moreover, the table above demonstrates the results of years of experience which classify between 5 and less than into 15 and greater than, the maximum number of the sample is (90) with (43.7\%) in the 15 year and greater than experiences, whereas the minimum number of the sample is (13) with $(6.3 \%)$ in the 5 year and less experiences. At last, the table presents that (58\%) of the study sample have an administrative job in different management levels while others have an operational job with (18\%) for each one.

\subsubsection{Reliability Test}

The instrument reliability was measured by using Cronbach Alpha test. The values of 
internal consistency between $(62.6 \%)$ to $(79.6 \%)$ are acceptable according to the accepted value. [9], if any value of internal consistency is more than $60 \%$, it will be accepted.

Table 2 shows that all variables have Alpha results which are more than (60\%). In the other word, all values are reasonable.

Table 1. Sample's distribution according to demographic information.

\begin{tabular}{|c|c|c|}
\hline \multicolumn{3}{|c|}{ Category frequency percentage } \\
\hline \multicolumn{3}{|l|}{ Gender } \\
\hline Male & 135 & 65.5 \\
\hline Female & 71 & 34.5 \\
\hline Total & 206 & 100 \\
\hline \multicolumn{3}{|c|}{ Experience } \\
\hline 5 year and less than & 13 & 6.3 \\
\hline Between 5 and less than 10 & 42 & 20.4 \\
\hline Between 10 and less than 15 & 61 & 29.6 \\
\hline 15 and greater than & 90 & 43.7 \\
\hline Total & 206 & 100 \\
\hline \multicolumn{3}{|c|}{ Qualification } \\
\hline Diploma & 52 & 25.2 \\
\hline B.Sc. & 42 & 20.4 \\
\hline High diploma & 55 & 26.7 \\
\hline Master & 48 & 23.3 \\
\hline $\mathrm{PhD}$ & 9 & 4.4 \\
\hline Total & 206 & 100 \\
\hline \multicolumn{3}{|l|}{ Job } \\
\hline Teacher & 37 & 18 \\
\hline Computer technician & 37 & 18 \\
\hline Science technician & 37 & 18 \\
\hline Librarian & 37 & 18 \\
\hline Administrative & 58 & 28 \\
\hline Total & 206 & 100 \\
\hline
\end{tabular}

Table 2. Cronbach alpha results.

\begin{tabular}{cc}
\hline Variables & Alpha \\
\hline Technology factor & 79.6 \\
Employee factor & 72.3 \\
Perceived usefulness & 77.5 \\
Perceived ease of use & 62.6 \\
Attitude toward use & 78.2 \\
\hline
\end{tabular}




\subsubsection{Statistical Results}

Based on virtual mean, the questions approval is measured, according to the following: (1) - (2.33) is a low effect, (2.34) - (3.37) is a medium effect and (3.38) - (5) is a high effect. Thus, the Table 3 demonstrates the results of mean and STD. Deviation for all questions in the questionnaire.

In general, It indicates that all questions have a positive attitude toward, this refers to the value of their means are in a high effect $(3.38-5)$. As well as, the above table presents that the mean of questions ( 40 and 48 ) have a highest value where the mean of question (40) is (4.76) with STD. deviation (0.43) and the STD. deviation of question (48) is (0.47), while the mean of question (3) has a lowest value which is (4.45) with STD. deviation (0.62). Thus, it can be considered that the questions (40 and 48) are the most important in questionnaire, while the question (3) is the least important.

\subsubsection{Collinearity Statistics Test}

In order to avoid Multicollinearity problem between two independent variables, it should perform the Multicollinearity statistics test which includes Tolerance and Variance Inflation Factor (VIF). Therefore, according to [10], the accepted value of Tolerance must be more than (0.10). In addition, the accepted value of VIF must be less than (10).

Table 4 shows the value of Tolerance which equal to (0.659) for both independent variables (Technology Factor and Employee Factor). Moreover, it can be seen the value of VIF which equal to (1.519) for both independent variables (Technology Factor and Employee Factor). Consequently, the value of Tolerance and VIF are accepted.

\subsubsection{Hypothesis Test}

First hypothesis: Technology factors have a significant influences associated with a perceived usefulness towards cloud ERP.

Based on simple regression, the hypothesis is tested. Table 5 demonstrates $\mathrm{f} \mathrm{calcu-}$ lated for the first hypothesis with (165.906), this value is significant due to the Sig $\mathrm{f}$ (0.000). As well as, the table presents $\boldsymbol{r}^{2}$ that indicates how the independent variable affect the dependent variable, here $\boldsymbol{r}^{2}$ value was (0.449). However, person correlation $(R)$ shows how the variables are correlated for each other; $r$ value was $(0.670)$. General rule indicates that when the significant level was less than (0.05), it suggests that the hypothesis is a statistically significant. Consequently, through those results, the perceived usefulness towards cloud ERP has been significantly explained by the technology factors.

Second hypothesis: Employee factors have a significant influences associated with a perceived usefulness towards cloud ERP.

Based on simple regression, the hypothesis is tested. Table 6 demonstrates $\mathrm{F}$ calculated for the first hypothesis with (84.177), this value is significant due to the Sig $\mathrm{f}$ $(0.000)$. As well as, the table presents $R^{2}$ that indicates how the independent variable affect the dependent variable, here $r^{2}$ value was (0.292). However, person correlation $(r)$ shows how the variables are correlated for each other; $r$ value was $(0.540)$. General rule 
Table 3. Means and standard deviations of sample's responses regarding perception of the variables.

\section{Questions mean STD. deviation}

Steps to complete a task in the cloud E-learning resources system follow a logic sequence.

$4.52 \quad 0.51$

Performing an operation in the cloud E-learning resources system led to a predicted result.

$4.50 \quad 0.60$

Screens of cloud E-learning resources system were clearly organized.

$4.58 \quad 0.50$

The cloud E-learning resources system was characterized by rapid response even at peak times.

$4.45 \quad 0.62$

The cloud E-learning resources system provided relevant information for work.

$4.60 \quad 0.49$

The cloud E-learning resources system presented the information in an appropriate format.

$4.50 \quad 0.52$

The information from the cloud E-learning resources system was up-to-date enough for my purposes.

$4.52 \quad 0.56$

The reliability of output information from cloud electronic learning resources system was high.

$4.51 \quad 0.60$

The cloud E-learning resources system provided the information when I need in time.

$4.59 \quad 0.52$

The cloud E-learning resources system had a modern looking interface.

$4.63 \quad 0.51$

The cloud E-learning resources system provided the right solution to my request.

$4.63 \quad 0.50$

The cloud E-learning resources system gave me prompt service.

$4.59 \quad 0.50$

The cloud E-learning resources system had a good interface to meet my needs and labor.

$4.59 \quad 0.50$

\begin{tabular}{lr}
\hline Technology factor & $4.516 \quad 0.54$ \\
\hline
\end{tabular}

I have experience to use handled device (Laptops, tablets, smart-phones...).

$4.67 \quad 0.55$

I have experience to use internet.

$4.64 \quad 0.57$

The cloud E-learning resources system is exactly what I need.

I am sure it was the right thing to adopt the cloud E-learning resources system.

Owning the cloud E-learning resources system has been a good experience.

I am satisfied with the performance of the cloud E-learning resources system service.

$4.71 \quad 0.49$

I am satisfied with the decision to work over the cloud E-learning resources system.

$4.66 \quad 0.55$

I am pretty satisfied with the cloud E-learning resources system which has been chosen.

Using the cloud E-learning resources system improved the quality of the work I do.

Using the cloud E-learning resources system gave me greater control over the activities in my work.

The cloud E-learning resources system enabled me to accomplish tasks more quickly.

The cloud E-learning resources system supported critical aspects.

The cloud E-learning resources system increased my productivity.

The cloud E-learning resources system improved my job performance.

The cloud E-learning resources system allowed me to accomplish more work than would otherwise be possible.

The cloud E-learning resources system enhanced my effectiveness on the job. 


\section{Continued}

Perceived usefulness

Overall, I found the cloud E-learning resources system interface easy to use.

My interaction with the cloud E-learning resources system was clear and understandable.

The cloud E-learning resources system required the fewest steps possible to accomplish what I want to do with it.

Using the cloud E-learning resources system is effortless.

I could use the cloud E-learning resources system without written instructions

I did not notice any inconsistencies when I use the cloud E-learning resources system.

I could recover from mistakes quickly and easily over the cloud E-learning resources system.

I could use the cloud E-learning resources system successfully every time.

Learning to use the cloud E-learning resources system interface was easy for me.

It was easy for me to become skillful at using the cloud E-learning resources system interface.

I found the cloud E-learning resources system interface to be flexible to interact with

I easily remembered how to use the cloud E-learning resources system.

Perceived Ease of use

I had a generally favorable attitude toward using the cloud E-learning resources system.

I believed it was a good idea to use the cloud E-learning resources system for my work.

I liked the idea of using the cloud E-learning resources system.

Using the cloud E-learning resources system provided me with a lot of enjoyment.

Overall, I enjoyed using the cloud E-learning resources system.

Attitude towards use

$4.62 \quad 0.51$

$4.74 \quad 0.44$

$4.75 \quad 0.48$

$4.69 \quad 0.51$

$4.68 \quad 0.52$

$4.69 \quad 0.53$

$4.75 \quad 0.46$

$4.71 \quad 0.48$

$4.71 \quad 0.45$

$4.76 \quad 0.43$

$4.74 \quad 0.46$

$4.74 \quad 0.47$

$4.76 \quad 0.44$

$\begin{array}{ll}4.73 & 0.47\end{array}$

$4.68 \quad 0.50$

$\begin{array}{ll}4.70 & 0.48\end{array}$

$4.69 \quad 0.54$

$\begin{array}{ll}4.68 & 0.49\end{array}$

$\begin{array}{ll}4.76 & 0.47\end{array}$

$\begin{array}{ll}4.70 & 0.50\end{array}$

Table 4. Collinearity statistics.

\begin{tabular}{ccc}
\hline \multirow{2}{*}{ Model } & \multicolumn{2}{c}{ Collinearity statistics } \\
\cline { 2 - 3 } & Tolerance & VIF \\
\hline Technology factor & 0.659 & 1.519 \\
Employee factor & 0.659 & 1.519 \\
\hline
\end{tabular}

Table 5. Test of hypothesis (1).

\begin{tabular}{cccccc}
\hline$r^{2}$ & $R$ & Sig t & $T$ & Sig F & $F$ \\
\hline 0.449 & 0.670 & 0.000 & 12.800 & 0.000 & 165.906 \\
\hline
\end{tabular}

${ }^{*}$ Significant at $(0.05)$ level.

Table 6. Test of hypothesis (2).

\begin{tabular}{cccccc}
\hline$r^{2}$ & $R$ & Sig t & $T$ & Sig F & $F$ \\
\hline 0.292 & 0.540 & 0.000 & 9.175 & 0.000 & 84.177 \\
\hline
\end{tabular}

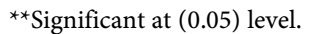


indicates that when the significant level was less than (0.05), it suggests that the hypothesis is a statistically significant. Consequently, through those results, the perceived usefulness towards cloud ERP has been significantly explained by the employee factors.

Third hypothesis: Technology factors have significant influence associated with a perceived ease of use towards cloud ERP.

Based on simple regression, the hypothesis is tested. Table 7 demonstrates F calculated for the first hypothesis with (96.822), this value is significant due to the Sig $f$ (0.000). As well as, the table presents $r$ that indicates how the independent variable affect the dependent variable, here $\boldsymbol{r}^{2}$ value was (0.485). However, person correlation $(r)$ shows how the variables are correlated for each other; $r$ value was (0.697). General rule indicates that when the significant level was less than (0.05), it suggests that the hypothesis is a statistically significant. Consequently, through those results, the perceived ease of use towards cloud ERP has been significantly explained by the technology factors.

Fourth hypothesis: Employee factors have significant influence associated with a perceived ease of use towards cloud ERP.

Based on simple regression, the hypothesis is tested. Table 8 demonstrates F calculated for the first hypothesis with (234.081), this value is significant due to the Sig $\mathrm{f}$ (0.000). As well as, the table presents $\boldsymbol{r}^{2}$ that indicates how the independent variable affect the dependent variable, here $r^{2}$ value was (0.534). However, person correlation $(r)$ shows how the variables are correlated for each other; $r$ value was $(0.731)$. General rule indicates that when the significant level was less than (0.05), it suggests that the hypothesis is a statistically significant. Consequently, through those results, the perceived usefulness towards cloud ERP has been significantly explained by the employee factors.

Fifth hypothesis: Perceived usefulness has significant influence associated with attitudes towards the use of cloud ERP.

Based on simple regression, the hypothesis is tested. Table 9 demonstrates $\mathrm{F}$ Table 7. Test of hypothesis (3).

\begin{tabular}{cccccc}
\hline$r^{2}$ & $R$ & Sig t & $T$ & Sig F & $F$ \\
\hline 0.485 & 0.697 & 0.000 & 9.840 & 0.000 & 96.822 \\
\hline
\end{tabular}

${ }^{*}$ Significant at $(0.05)$ level.

Table 8. Test of hypothesis (4).

\begin{tabular}{cccccc}
\hline$r^{2}$ & $R$ & Sig t & $T$ & Sig F & $F$ \\
\hline 0.534 & 0.731 & 0.000 & 15.298 & 0.000 & 234.081 \\
\hline
\end{tabular}

${ }^{*}$ Significant at $(0.05)$ level.

Table 9. Test of hypothesis (5).

\begin{tabular}{cccccc}
\hline$r^{2}$ & $R$ & Sig t & $T$ & Sig F & $F$ \\
\hline 0.379 & 0.616 & 0.000 & 11.169 & 0.000 & 124.740 \\
\hline
\end{tabular}

**Significant at (0.05) level. 
Table 10. Test of hypothesis (6).

\begin{tabular}{cccccc}
\hline$r^{2}$ & $r$ & Sig t & $T$ & Sig F & $F$ \\
\hline 0.376 & 0.614 & 0.000 & 11.098 & 0.000 & 123.156 \\
\hline
\end{tabular}

${ }^{*}$ Significant at $(0.05)$ level.

calculated for the first hypothesis with (124.740), this value is significant due to the Sig $\mathrm{f}$ (0.000). As well as, the table presents $\boldsymbol{r}^{2}$ that indicates how the independent variable affect the dependent variable, here $\boldsymbol{r}^{2}$ value was (0.379). However, person correlation $(r)$ shows how the variables are correlated for each other; $r$ value was (0.616). General rule indicates that when the significant level was less than (0.05), it suggests that the hypothesis is a statistically significant. Consequently, through those results, the attitudes towards the use of cloud ERP have been significantly explained by the perceived usefulness.

Sixth hypothesis: Perceived ease of use has significant influence associated with attitudes towards the use of cloud ERP.

Based on simple regression, the hypothesis is tested. Table 10 demonstrates $\mathrm{F}$ calculated for the first hypothesis with (123.156), this value is significant due to the Sig $\mathrm{f}$ (0.000). As well as, the table presents $\boldsymbol{r}^{2}$ that indicates how the independent variable affect the dependent variable, here $\boldsymbol{r}^{2}$ value was (0.376). However, person correlation $(r)$ shows how the variables are correlated for each other; $r$ value was (0.614). General rule indicates that when the significant level was less than (0.05), it suggests that the hypothesis is a statistically significant. Consequently, through those results, the attitudes towards the use of cloud ERP have been significantly explained by the perceived ease of use.

\section{Discussion and Conclusion}

The main purpose of this study is to investigate the employees' attitude towards the use of cloud ERP system in QRC in Jordanian Education Ministry. The effectiveness technology and employee factors have been checked in this study. In addition, the perceived usefulness, perceived ease of use and attitude towards the use of cloud ERP have been examined.

Thus, the findings of study show the strong supports for the study hypothesis. Moreover, the results of the influence of technology factors on perceived usefulness towards cloud ERP were strong. In addition, the findings of the influence employee factors on perceived ease of use towards cloud ERP were strong. This is corresponding with literature researches which claimed that there is a positive support of the technology factors and employee factors on the perceived usefulness towards cloud ERP.

In addition, this study has explored the results of the influence perceived usefulness and ease of use on the attitude towards of the use cloud ERP system. Thus; this is corresponding with [6] which found that the perceived usefulness has a strong influence on the attitudes towards the use of cloud ERP system. [4] found that there was a positive influence of perceived ease of use of EduWave system on the attitude towards use 
the system.

Consequently, based on TAM and literature, it can be concluded that QRC employees enjoy working through cloud ERP system to perform their duties. In addition, the performance and productivity of the QRC employees are increased through using the cloud ERP system. The important result was the mobility advantage of the cloud ERP system that can be used anytime, anywhere and any device which can help them to perform any work in the time they want.

\section{References}

[1] Patterson, A. (2005) Information Systems-Using Information. Learning and Teaching Scotland.

[2] Mijač, M., Picek, R. and Stapić, Z. (2013) Cloud ERP System Customization Challenges. Central European Conference on Information and Intelligent System, 18-20 September 2013, 133.

[3] Raihana, G.F.H. (2012) Cloud ERP-A Solution Model. International Journal of Computer Science and Information Technology \& Security, 2.

[4] Abu-Shanab, E. (2014) E-Learning System's Acceptance: A Comparative Study. International Journal of Web-Based Learning and Teaching Technologies, 9, 1-13. http://dx.doi.org/10.4018/ijwltt.2014100101

[5] Chen, S., Li, S. and Li, C. (2011) Recent Related Research in Technology Acceptance Model: A Literature Review. Australian Journal of Business and Management Research, 1, 124-127.

[6] Davis, F.D. (1989) Perceived Usefulness, Perceived Ease of Use, and User Acceptance of Information Technology. MIS Quarterly, 13, 319-340. http://dx.doi.org/10.2307/249008

[7] Roca, J.C., Chiu, C.-M. and Martınez, F.J. (2006) Understanding e-Learning Continuance Intention: An Extension of the Technology Acceptance Model. International Journal of Human-Computer Studies, 64, 683-696. http://dx.doi.org/10.1016/j.ijhcs.2006.01.003

[8] Radhakrishna, R.B. (2007) Tips for Developing and Testing Questionnaires/Instruments. Journal of Extension, 45, Article 1TOT2. http://www.joe.org/joe/2007february/tt2.php

[9] Malhotra, N.K. (2004) Marketing Research. Prentice Hall, New Jersey.

[10] Mason, G. (1987) Coping with Collinearity. The Canadian Journal of Program Evaluation, 2, 87-93. 
Submit or recommend next manuscript to SCIRP and we will provide best service for you:

Accepting pre-submission inquiries through Email, Facebook, LinkedIn, Twitter, etc. A wide selection of journals (inclusive of 9 subjects, more than 200 journals)

Providing 24-hour high-quality service

User-friendly online submission system

Fair and swift peer-review system

Efficient typesetting and proofreading procedure

Display of the result of downloads and visits, as well as the number of cited articles

Maximum dissemination of your research work

Submit your manuscript at: http://papersubmission.scirp.org/

Or contact ijcns@scirp.org 